\title{
Forças internas e a conservação do momento angular
}

\author{
André Herkenhoff Gomes*10 \\ ${ }^{1}$ Universidade Federal do Espírito Santo, Departamento de Ciências Naturais, Campus São Mateus, ES, Brasil.
}

Recebido em 09 de Janeiro, 2018. Revisado em 16 de Fevereiro, 2018. Aceito em 17 de Março, 2018.

Sendo um dos pontos centrais dos cursos de mecânica clássica, a lei da conservação do momento angular provê relações simples entre diferentes estados de um sistema com dinâmica rotacional. No entanto, tal abordagem falha em elucidar os processos internos que levam de um estado a outro. Para preencher esta lacuna, fazemos uma análise diferente de situações simples que exibem conservação do momento angular, dando enfoque às forças e torques internos que agem nos sistemas analisados quando estes mudam de estado rotacional. Tal abordagem deve mostrar-se útil para uma compreensão maior da dinâmica observada, especialmente uma vez que as situações abordadas são comuns em demonstrações realizadas em sala de aula.

Palavras-chave: Momento angular, lei de conservação, mecânica.

One of the main points of classical mechanics courses, the conservation law of angular momentum provides simple relations among different states of a system exhibiting rotational dynamics. Nonetheless, such approach fails to elucidate the internal processes that lead from one state to another. Filling this gap, we perform a different analysis of simple situations where angular momentum is conserved, focusing on the internal forces and torques of the analyzed systems when they change their rotational states. Such approach may prove itself useful for a deeper understanding of the observed dynamics, especially since the discussed situations are commonly seen in classroom demonstrations.

Keywords: Angular momentum, conservation law, mechanics.

Imagine-se participando da clássica demonstração de conservação do momento angular na qual você está sobre o centro de uma mesa giratória segurando um haltere em cada mão. Com os braços abertos, você é posto a girar em torno da direção vertical (Fig. 1a). Enquanto gira, você fecha os braços para aproximar os halteres ao próprio corpo e, ao fazer isso, repentinamente gira mais rápido (Fig. 1b). Ao ser perguntado sobre o que aconteceu, você responde sem receios: ao trazer os halteres para perto do eixo de rotação, o momento de inércia total $I$ diminui; como não há torques externos, a conservação do momento angular diz que a velocidade angular $\omega$ deve aumentar de modo a manter o produto $I \omega$ constante.

A demonstração descrita fascina, mas a explicação posterior, apesar de correta, oferece pouca intuição a respeito do fenômeno observado, que permanecerá envolto em mistério na mente dos estudantes. Em particular, nada é dito a respeito do mecanismo interno que causa a aceleração angular repentina quando você aproxima os halteres ao próprio corpo, nem da desaceleração que surge quando estes são afastados. O que causa essas variações de velocidade angular que acabam por manter o momento angular conservado?

Nestas notas, analisaremos algumas situações nas quais o momento angular é conservado e buscaremos explica-

*Endereço de correspondência: andre.h.gomes@ufes.br

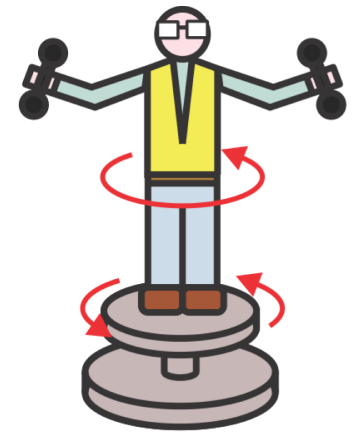

(a)

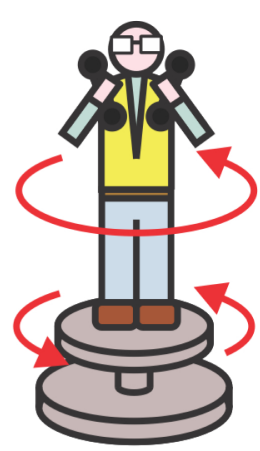

(b)
Figura 1

ções menos abstratas que a exemplificada anteriormente. Veremos que o mecanismo por trás da conservação do momento angular é bastante simples: forças internas de contato causadas por movimentos relativos entre partes do sistema. Antes de entrar em detalhes, discutiremos uma situação simples de conservação do momento linear que servirá como base para raciocínios que usaremos nos casos de dinâmica rotacional.

Considere a seguinte situação: uma caixa de massa $M$ deslizando com velocidade constante $\boldsymbol{V}$ sobre uma superfície horizontal muito lisa, de atrito desprezível. A caixa não tem tampa e, em certo instante, um bloqui- 
nho de massa $m$ cai verticalmente em seu interior, onde pode deslizar sem atrito. Nesta primeira colisão as únicas forças são verticais, logo a velocidade horizontal de ambos se mantém como antes da colisão (Fig. 2a). A partir de então, por ser sempre nula a força resultante sobre o sistema constituído pelo bloco e pela caixa, o momento linear deste é conservado em todos instantes, inclusive durante a colisão entre a parede traseira da caixa e o bloco, que consideraremos ser completamente inelástica. Com isso, a velocidade final do sistema será $M \boldsymbol{V} /(M+m)$, que naturalmente é menor que a velocidade inicial da caixa vazia. O que exatamente fez a caixa perder velocidade? Sabemos que foi o bloquinho, mas como? Após cair dentro da caixa, o bloquinho desliza e atinge a parede traseira desta, exercendo uma força média $-\boldsymbol{F}$ durante um intervalo $\Delta t$, tendendo a freiá-la. Em contrapartida, esta parede exerce sobre o bloquinho uma força média $\boldsymbol{F}$ de mesmo módulo mas sentido oposto, acelerando-o para frente (Fig. 2b). A caixa está perdendo velocidade e o bloquinho ganhando. Considerando que após o intervalo $\Delta t$ ambos terão a mesma velocidade (Fig. 2c), a variação dos seus momentos terá

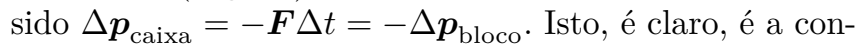
servação do momento linear do sistema: conforme a caixa perde momento, o bloquinho o ganha ${ }^{1} \mathrm{O}$ mecanismo interno que garante esta conservação deve-se às forças de contato entre a caixa e o bloquinho, que só existem enquanto existir velocidade relativa entre os dois.

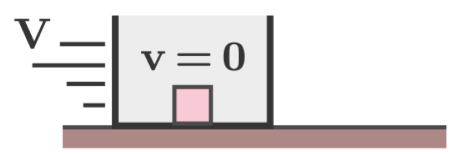

(a)

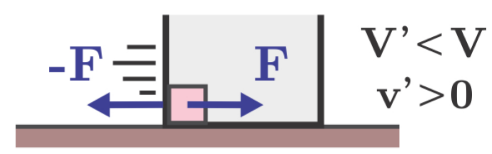

(b)

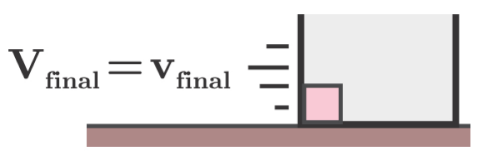

(c)

Figura 2

\footnotetext{
${ }^{1}$ Note que, na ausência de uma força externa resultante, partindo-se da hipótese de que a terceira lei de Newton é válida, chegamos à conclusão de que o momento linear é conservado. Esta é uma conclusão geral e, para um sistema de partículas interagindo por meio de forças de contato, o caminho inverso é sempre verdadeiro: da hipótese de conservação do momento linear segue a validade da terceira lei de Newton. Os detalhes fogem ao escopo destas notas, mas mencionamos que conclusões análogas podem ser obtidas para o momento angular e a terceira lei de Newton quando o sistema também exibe dinâmica rotational 1 .
}

Antes de partir para outra situação, vamos conferir que das leis de Newton segue a mesma expressão para a velocidade final do sistema que seria obtida por meio da conservação do momento linear. Supondo que esta velocidade seja $\boldsymbol{V}^{\prime}$, a segunda lei de Newton para o bloquinho fornece a força média com que a parede traseira da caixa o acelera, $\boldsymbol{F}=m \boldsymbol{V}^{\prime} / \Delta t$. A aceleração média da caixa devido a reação a esta força é dada por $\boldsymbol{a}=$ $-\boldsymbol{F} / M=-m \boldsymbol{V}^{\prime} / M \Delta t$. Com a equação horária para a velocidade da caixa, $\boldsymbol{V}(t)=\boldsymbol{V}_{\mathbf{0}}+\boldsymbol{a} t$, obtemos $\boldsymbol{V}^{\prime}=$ $\boldsymbol{V}-m \boldsymbol{V}^{\prime} / M$, que fornece a velocidade final do sistema $\boldsymbol{V}^{\prime}=M \boldsymbol{V} /(M+m)$, como esperado.

Para o análogo rotacional do exemplo anterior, imagine uma barra reta e uniforme com dois baldes idênticos, cada um preso em uma extremidade. O conjunto possui momento de inércia $I$ e gira com velocidade angular $\boldsymbol{\omega}$ constante em torno de um eixo vertical fixo que atravessa o seu centro de massa. Digamos que não exista qualquer atrito que interfira no movimento. Em certo momento, uma bolinha de massa $m$ cai verticalmente no interior de um dos baldes (Fig. 3). Como não há torque externo resultante ao longo do eixo de rotação, a conservação do momento angular estabelece a velocidade angular final do sistema como sendo $I \boldsymbol{\omega} /\left(I+m R^{2}\right)$, sendo $R$ a distância da bolinha ao eixo de rotação. Naturalmente, o sistema passa a girar de modo mais lento. O mecanismo interno que causa isso está associado às forças de contato entre a bolinha e o balde, que atuam de modo similar às do exemplo anterior, mas desta vez causando torques internos. Este mecanismo freia a barra por meio de um torque médio $-\boldsymbol{\tau}$ que atua durante um intervalo $\Delta t \mathrm{e}$ acelera a bolinha por meio de um torque oposto $\tau$. Estes torques internos persistem enquanto existir velocidade relativa entre o balde e a bolinha. Assim que ambos começarem a girar com a mesma velocidade, a variação dos momentos angulares terá sido $\Delta \boldsymbol{L}_{\text {barra }}=-\boldsymbol{\tau} \Delta t=$ $-\Delta \boldsymbol{L}_{\text {bola }}$, o que corresponde à conservação do momento angular.

Semelhante ao exemplo de dinâmica linear, podemos conferir que a expressão para a velocidade angular final do sistema também pode ser obtida a partir das leis de Newton. Supondo que esta velocidade seja $\boldsymbol{\omega}^{\prime}$, o torque médio que acelera a bolinha conforme ela inicia um movimento circular no plano horizontal é $\boldsymbol{\tau}=\boldsymbol{R} \times \boldsymbol{F}=m R^{2} \boldsymbol{\omega} / \Delta t$. A

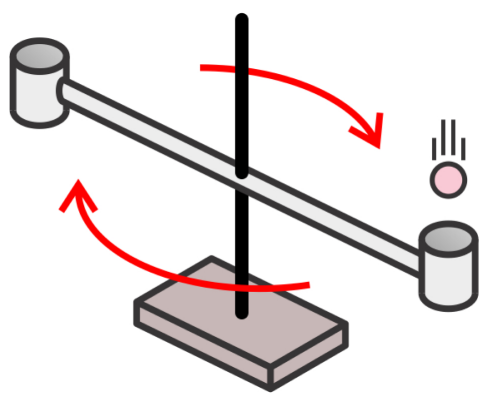

Figura 3 
reação a este torque desacelera a barra com uma aceleração angular $\boldsymbol{\alpha}=-\boldsymbol{\tau} / I=-m R^{2} \boldsymbol{\omega} / I \Delta t$. Análogo ao caso linear, com a equação horária para a velocidade angular da barra, $\boldsymbol{\omega}(t)=\boldsymbol{\omega}_{\boldsymbol{o}}+\boldsymbol{\alpha} t$, obtemos $\boldsymbol{\omega}^{\prime}=\boldsymbol{\omega}-m R^{2} \boldsymbol{\omega} / I$, resultando em $\boldsymbol{\omega}^{\prime}=I \boldsymbol{\omega} /\left(I+m R^{2}\right)$.

Vamos retornar à demonstração de sala de aula que mencionamos no início destas notas (Fig. 1). Para tornar a discussão mais clara, vamos modelá-la de modo simples: um eixo vertical fixo que atravessa perpendicularmente o centro de uma barra reta e uniforme representa você em pé de braços abertos; as extremidades da barra atravessam o eixo de discos maciços que representam os halteres. Para representar o seu abrir e fechar de braços durante a demonstração, considere que os discos podem deslizar sem atrito ao longo da barra, mas que suas posições são limitadas por fios leves e inextensíveis de comprimento ajustável - por exemplo, se os encurtamos, os discos são puxados ao longo da barra em direção ao centro. Considerando a situação inicial na qual você gira com os braços abertos enquanto segura os halteres, consideramos a barra girando com os discos maciços inicialmente nas extremidades - lembre-se que fios impedem que os cilindros deslizem para fora da barra. Esta situação está representada na Fig. 4a, onde vemos o sistema de cima para baixo. Para referência futura, marcamos os pontos 1 e 2 sobre a barra e indicamos as suas velocidades por meio de setas - analisaremos o lado esquerdo da barra, sendo a análise do direito análoga.

A situação em que você fecha os braços, aproximando os halteres ao seu corpo, equivale a encurtarmos o fio que segura cada disco no nosso modelo. Nesta situação, uma força radial desloca os discos das extremidades para pontos próximos ao centro da barra. Como na Fig. 4b, o disco da esquerda, por exemplo, momentaneamente mantém a mesma velocidade de rotação ao deslizar do ponto 1 ao 2 , pois a força que o puxa é perpendicular à esta velocidade ${ }^{2}$ Rapidamente esta situação muda, pois o disco chega ao ponto 2 com velocidade maior que a da barra neste ponto, o que cria forças de contato entre as paredes internas do disco e a barra. Assim, o disco produz um torque que acelera a barra e a barra produz outro contrário que desacelera o disco. Estes torques internos desaparecem quando as velocidades da barra e do disco se igualam (Fig. 4c), de modo análogo ao discutido nos exemplos anteriores. A velocidade final de rotação em cada ponto do sistema é maior que do que quando os discos estavam nas extremidades. Logo, o efeito de aproximar-se os discos ao eixo de rotação é aumentar a velocidade angular do sistema, em acordo com o esperado pela conservação do momento angular.

No contexto da demonstração que você realiza como na Fig. 1, vemos que a sua velocidade angular aumenta

\footnotetext{
${ }^{2}$ Provavelmente você já notou isso ao brincar de girar uma pedra presa a um barbante. Durante o giro, a pedra começa a girar mais rápido quando encurtamos o fio - como ditado pela relação $v=\omega r$, pois sendo a velocidade $v$ a mesma antes e depois de encurtarmos o fio, reduzir o raio de giro $r$ deve fazer a velocidade angular $\omega$ aumentar.
}

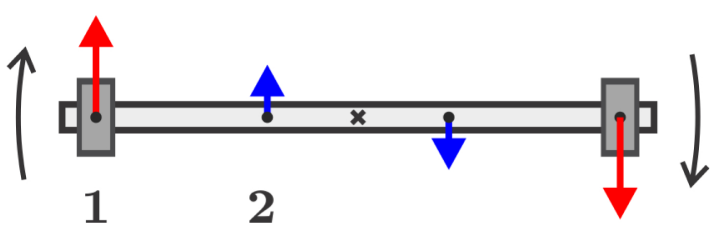

(a)

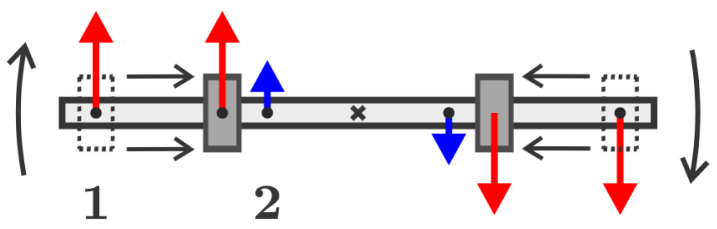

(b)

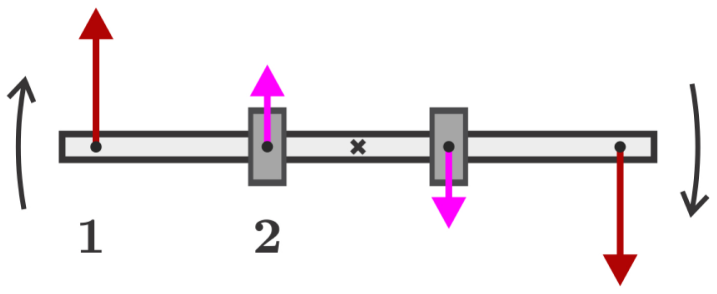

(c)

Figura 4

quando você traz os halteres para perto do seu corpo porque o movimento mais veloz dos halteres literalmente te carrega junto a eles. E por que a velocidade angular diminui quando você abre os braços e afasta os halteres? Tenhamos em mente o modelo descrito no exemplo anterior, mas neste caso com a situação inicial correspondendo àquela da Fig. 4c e a final a da Fig. 4a. Quando são afastados do seu corpo, os halteres partem de uma região de menor velocidade de rotação para outra de maior, o que corresponderia a ir do ponto 2 ao 1 na Fig. 4c mantendo-se constante a velocidade de rotação inicial (seta rosa). Com os braços abertos, a velocidade momentaneamente menor dos halteres oferece resistência ao movimento de rotação, fazendo com que cada ponto do sistema tenha velocidade final de rotação menor que a inicial, o que está associado a uma redução na velocidade angular do sistema.

Até agora, escolhemos exemplos de dinâmica rotacional nos quais a direção do vetor momento angular de cada parte do sistema é sempre fixa. Isso permitiu discussões da conservação do momento angular focadas apenas nas relações entre alterações no momento de inércia e consequentes alterações na velocidade angular do sistema. Por fim, vamos considerar outra demonstração comum em sala de aula na qual inicialmente ocorre mudança apenas na direção do momento angular das partes do sistema.

Imagine-se de pé sobre o centro de uma mesa giratória segurando, inicialmente na posição horizontal, um eixo em torno do qual uma roda está girando livremente (Fig. 5a). Nesta demonstração, conforme a roda é inclinada para um lado ou para o outro, vemos você e todo o aparato começarem a girar em torno da vertical (Fig. 5b). 


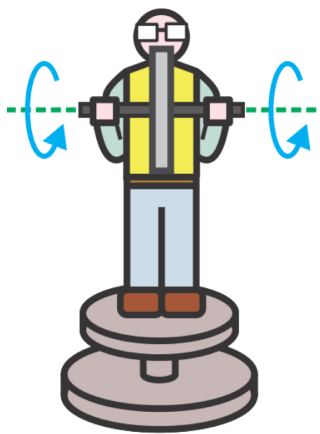

(a)

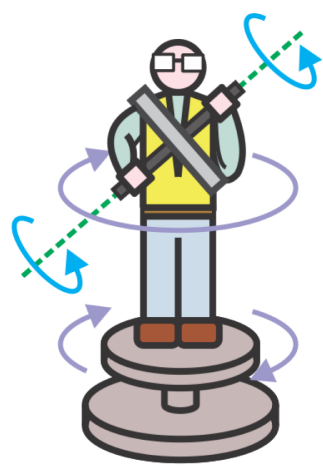

(b)
Figura 5

A explicação nós sabemos: inicialmente a componente vertical do momento angular do sistema é nula e, como ditado por sua lei de conservação, assim deve continuar, pois não há torque externo resultante nesta direção $3^{3}$ $\mathrm{O}$ momento angular da roda adquire uma componente vertical quando a roda é inclinada, logo o sistema como um todo (roda, eixo, você e mesa giratória) deve adquirir rotação em torno da vertical em um sentido que cancele esta componente.

Como atuam as forças internas que fazem o sistema como um todo adquirir uma rotação? Considere o eixo da roda inicialmente na horizontal e a roda girando como na Fig. 5a. Para inclinar a roda como na Fig. 5b, você aplica forças no seu eixo (setas pretas da Fig. 6) que criam forças de contato (setas vermelhas) que a inclinará. Se a roda não estivesse girando, o efeito destas forças seria, de fato, somente incliná-la. Como a roda está girando, as forças de contato tendem a também rotacionar o seu plano de giro como na Fig. 7 , onde as velocidades tangenciais foram indicadas em dois pontos em um instante anterior (setas azuis) e em um instante posterior (setas roxas) à ação das componentes horizontais das forças de contato (setas vermelhas) ${ }^{4}$ Portanto, o torque que você aplica no eixo da roda, além de incliná-la, também produz outra alteração na orientação do seu plano de giro: uma rotação em torno da vertical. Como você está segurando o eixo

\footnotetext{
${ }^{3} \mathrm{Na}$ situação inicial existe componente horizontal do momento angular, e esta muda de direção conforme o sistema, como um todo, gira. De fato, esta componente não é conservada. Para você inclinar a roda, um dos lados do seu eixo deve ser movido para cima e, ao fazer isso, uma força de reação empurra você para baixo. Como esta força não está contida no plano inicial da roda, a resultante normal do piso contra você também não estará. Esta força normal é, no fim, a responsável pelo torque externo (horizontal e perpendicular ao eixo da roda) que faz o momento angular inicial (horizontal) do sistema não ser conservado.

${ }^{4}$ Você pode verificar essa conclusão de modo simples por meio de uma situação análoga. Faça rolar um disco sobre uma superfície plana (use uma moeda ou a tampa de um pote, por exemplo). Durante o movimento, toque seu topo de leve, perpendicularmente ao plano de giro. As forças associadas a este toque e ao atrito entre o disco e a superfície farão o papel das forças indicadas na Fig. 7. Observe que o disco além de se inclinar tendendo a cair também irá rolar em outra direção como efeito da rotação adicional do seu plano de giro.
}

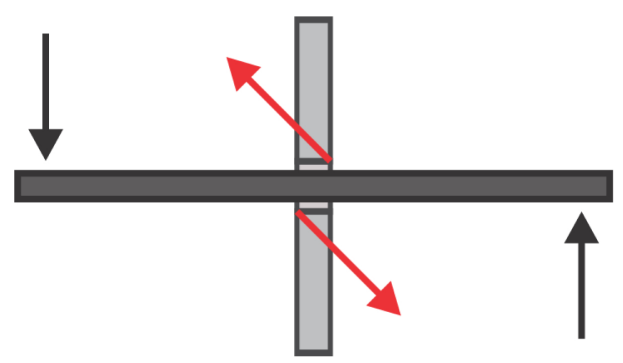

Figura 6

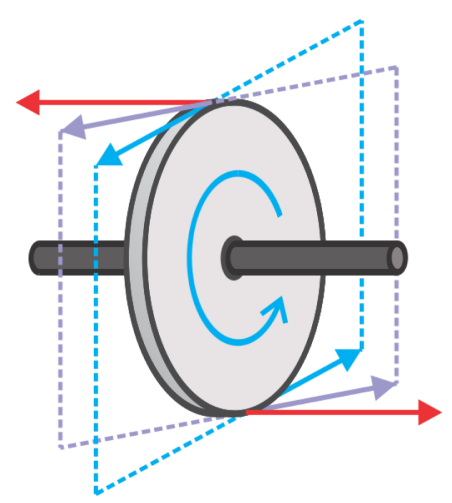

Figura 7

da roda e está sobre uma mesa que pode girar livremente, esta alteração adicional força todo o sistema a girar em torno da vertical.

Note que o sentido do giro adicional que o sistema adquire é consistente com o esperado pela conservação da componente vertical do momento angular. Considerando a Fig. 5, ao ser inclinada, a roda adquire componente vertical do momento angular que aponta para cima, logo o sistema deve girar no sentido indicado (setas roxas) para adquirir momento angular vertical que aponte para baixo. De fato, vemos pela a Fig. 7 que o plano da roda tende a girar neste mesmo sentido.

Acreditamos que as análises apresentadas nestas notas, no contexto das demonstrações das Figs. 1 e 5, podem ser adaptadas para exposição em sala de aula, trazendo o benefício de uma compreensão mais fundamental dos mecanismos envolvidos na conservação do momento angular. Estas discussões também podem ser utilizadas para motivar o estudo de situações mais complexas. Por exemplo, simples adaptações do último exemplo que discutimos podem ser utilizada para se compreender os movimentos de precessão [2] 3] e nutação [4 5$]$ de um giroscópio.

\section{Referências}

[1] H.M. Nussenzveig, Curso de Física Básica: Mecânica (Blucher, São Paulo, 2013), $5^{\mathrm{a}}$ ed.

[2] G.D. Scott, Am. J. Phys. 25, 370 (1957).

[3] P.L. Edwards, Am. J. Phys. 45, 1194 (1977).

[4] E.F. Barker, Am. J. Phys. 28, 808 (1960).

[5] P.M. Rinard, Am. J. Phys. 34, 365 (1966). 